\title{
PSYCHOTROPIC DRUGS DURING LACTATION
}

\author{
Amlan Kusum Jana, MD, DPM \\ Assistant Professor \\ KPC Medical College \& Hoispital, Kolkata \\ Email : amlankjana@gmail.com
}

\section{INTRODUCTION}

Antipsychotic use during lactation is often for postpartum (1-2/1000)/puerperal psychosis. Children born out of mothers with schizophrenia/ schizoaffective disorder who are symptomatic are at increased risk of developing physiologic, psychological and personality development disturbances in the adulthood (Dellisch 1989; Schubert and McNeil 2003; 2004). To make matters worse, women are at risk of relapse after delivery even if they were remitted during the entire course of pregnancy (Nishizawa et al. 2007).

Since the risk benefit analysis of these drugs is inconclusive if the situation demands starting an antipsychotic the choice should be based on the efficacy of the drug in general except for clozapine (till its efficacy is proved beyond doubt as it has propensity to get secreted in milk in high concentration thereby exposing the baby to risk of agranulocytosis) and olanzapine (high risk of EPS). On the other hand continuation of antipsychotics duringlactation in a patient whohas been maintaining well on it is always advised and lactating period is not a suitable time for pharmacological switches (Gentile 2008). Still in dicey situations when one has to choose between favouring breast feeding and temporarily withdrawing antipsychotics and continuing antipsychotics with discontinuation of breast feeding the second option should be preferred (Gentile 2006).

The current review gives a brief description of the safety of psychotropic drugs during lactation so that an informed decision can be made about choosing the most appropriate among them during this potentially critical period of a woman's life.

\section{ANTIPSYCHOTICS}

Aripiprazole: It is secreted in milk in rodents but its role in human beings is uncertain expect for a case report (Mendhekar et al. 2006) mentioning lactation failure (Gentile 2008).

Clozapine:Itseffects onlactation areinferred through anecdotal reports only with reports including high concentration in breast milk (Barnas et al. 1994) to neurodevelopmental delay*(Mendhekar 2007).* The baby was exposed to clozapine prenatally as well.

Olanzapine : Studies on its effects on lactation (Kasper et al. 1999; Croke et al. 2002) show that infant exposure of drugs through breast milk is relatively low $(0.66-2.66 \%)$. The effects seen in the infant were jaundice, sedation, poor sucking and temporary motor developmental delay (Kirchheiner et al. 2000).

Quetiapine : This drug is also considered safe to use during lactation with drug levels ranging from $0.09-0.43 \%$ to a maximum of $6 \%$ (Rampono et al. 2007). Mildly delayed mental performance and slight physical delay is all that is reported (Misri et al. 2006).

Risperidone : The levels of the drug and its metabolites in milk has been reported to range from $0.84 \%$ to $4.7 \%$ (Ilett et al. 2004) and there is no reported adverse effect (Gentile 2008).

Ziprasidone : A single case report (Schlotterbeck et al. 2009) which mentions a 'low' concentration of this molecule in breast milk is the only available human data at the moment. 
Structural/behavioural teratogenicity: Case reports showing transient unwanted effects on neonatal cardiac rhythm with aripiprazole exposure have been published. Perinatal complications including transient floppy infant syndrome, retinopathy, and severe neonatal hypoxemic encephalopathy have been reported with clozapine exposure. Pinkofsky et al. (1997) have raised the issue of potential clozapine-induced fetal agranulocytosis. Perinatal complications of various degrees of severity may also occur with risperidone exposure, ranging from withdrawal reactions to seizures.

\section{FGAS}

Haloperidol : The case reports in the past even with solid methodology (Yoshida et al. 1998) showed no adverse effects to babies who were breast fed by mothers on haloperidol.

Flupenthixol, Chlorprothixene, and Zuclopenthixol : Only one case report (Matheson and Skjaeraasen 1988) is available to show its effects on lactation and it shows no adverse effect.

Phenothiazines : Yoshida et al. (1998) reports CPZ (Y) to be safe in lactating women as had been confirmed by earlier case series study (Kris and Carmichael 1957). Wiles et al. (1978) however reported drowsiness and lethargy in a baby where the CPZ concentration in milk was quite high (not mentioned in figures). TFP has shown no adverse effect in a case report (Yoshida et al. 1998). Concentrations of CPZ, THR, TFP in milk is $<$ HPL. In lowest possible dose and with supervision $\mathrm{BF}$ can be continued with these medications but CLZ is contraindicated with BF.

Perinatal/behavioural teratogenicity : Perinatal complications arising out of late exposure to HPL ranges from withdrawal symptoms to instability of body temperature and those from CPZ includes extrapyramidal signs, which may persist up to 1 year of age; respiratory distress; seizures; and transient neurodevelopmental delay.

\section{SUMMARY FOR ANTIPSYCHOTICS}

A recent review (Klinger et al. 2013) summarizes the levels of acceptability of various antipsychotics during breast feeding. Olanzapine and quetiapine were categorized as acceptable for breastfeeding. Chlorpromazine, haloperidol, risperidone and zuclopenthixol were categorized as possible for breastfeeding under medical supervision. Breastfeeding cannot be currently recommended for the following medications: aripiprazole, asenapine, chlorprothixene,clozapine,droperidol,fluphenazine, flupenthixol, iloperidone, lurasidone, paliperidone, perphenazine, pimozide, trifluoperazine, thiothixene and ziprasidone.

\section{SSRIS \& SNRIS}

The selective serotonin reuptake inhibitors (SSRIs), particularly fluoxetine, are a medication class that has been well studied in pregnancy and lactation. The findings are summarized below.

Fluoxetine : Relatively higher concentrations have been noted for fluoxetine in breast milk and infant plasma. Fluoxetine produced the highest proportion (22\%) of infant levels that were detected, and these were elevated to $10 \%$ of the average maternal level among a total of 57 studies measuring drug levels in milk from 1966 to 2002 (Weissman et al. 2004). The literature includes cases of adverse events, mainly with the use of fluoxetine, which included uneasy sleep, colic, irritability, poor feeding, drowsiness, hyperglycemia and glycosuria, peripheral cyanosis and unresponsiveness to stimuli (Fortinguerra et al. 2009). Epperson et al. (2003) in their study suggested that most infants continued to breastfeed without experiencing clinically significant changes in platelet 5-HT transport while their mothers were being treated with 20 to $40 \mathrm{mg}$ of fluoxetine though the mothers had their platelet 5-HT transporters blocked.

Sertraline : Regarding its use in breast feeding Epperson et al. (2001) showed that though the platelet 5-HT transporters in mothers were blocked no such 
effects were seen in babies. Stowe et al. (2003) showed that the milk contained highest concentration of SRT 9 hours after maternal intake of the medicine. These results suggested that discarding the breast milk nine hours after the maternal dose decreased the infant daily dose of SRT by a mean of $17 \%$ and, again, no adverse events were seen in any of the infants.

Citalopram : Citalopram has typically been the highest concentration SSRI antidepressant, when it has been compared to sertraline, paroxetine and fluoxetine. However, in studies those have only measured citalopram, negligible or no effects have been noted (Field 2008). However, high doses in lactating women can be risky as it is secreted in milk in high concentration (Eberhard-Gran et al. 2006).

Paroxetine : Paroxetine is said to be found in higher concentrations in infant milk and serum than sertraline, but in lower concentrations than fluoxetine and citalopram with concentration ranging from $0.7 \%$ to $2.9 \%$ (Ohman et al. 1999). Though higher concentrations in hindmilk (vs foremilk) has been reported (Stowe et al. 2000; Misri et al. 2000) no adverse effect has been reported in the breast fed babies not even over a period of 1 year (Merlob et al. 2004). However the authors recommended lowest possible dose of PXT (20mg/day) to be taken at bed time.

\section{FLUVOXAMINE}

Venlafaxne : It is recommended that breast-fed infants of mothers taking venlafaxine be closely observed (Ilett et al. 1998).

\section{TCAS}

TCAs have been widely used during lactation (Weissman et al. 2004). Doxepin should be avoided during lactation due to one case report of an infant with respiratory depression (Matheson et al. 1985).

Regarding their useinlactation as reviewed by Buistet al. (1990) the milk/ plasma ratio of drug concentration has ranged from $1.23 / 1.63$ for Desipramine to
1.62/0.88 for Amitriptyline. Data with Doxepin is concerning with reports of respiratory depression, hypotonia, poor sucking and swallowing reflex and vomiting (Matheson et al. 1985). The total dose to which the child is exposed is considerably less than (perhaps 0.001-0.01 times) that to which the mother is exposed. The recommendation to breastfeed or not with tricyclic antidepressants should not be based on this datum alone. It should be borne in mind that prolonged exposure to small doses of drugs, which have profound effects on catecholaminergic and serotonergic neuronal systems, could have adverse effects on a developing central nervous system. To err on the side of caution would seem prudent in the absence of any data to the contrary (Buist et al. 1990).However Fortinguerra et al. (2009) have reviewed literature and stated that amitriptyline, clomipramine, dosulepin and imipramine can be safely used during lactation but caution has to be exercised with any other TCA. TCAs usually can be given in lactating women, especially if the baby is $>10$ weeks of age. Anticholinergics, however are better avoided as infants are particularly sensitive to their adverse effects.

\section{MAOIs}

Due to dietary and medication restrictions, along with the potential to cause hypertensive crises, this class should not be used during pregnancy and breastfeeding (Newport et al. 2001).

\section{OTHERS}

Bupropion is classified as category B due to no adverse outcomes in animal studies. However, limited human data (case series by Davis et al. 2009) on use in pregnancy and lactation are available for bupropion.

Mirtazapine : Lactation studies for mirtazapine are limited to a case report of a breast-fed infant who did not show adverse effects (Aichhorn et al. 2004). Fortinguerra et al. (2009) say mirtazapine can be safely used during lactation. 


\section{Psychotropic drugs during lactation}

\section{MOOD STABILIZERS}

Lithium: No reports regarding long-term neurobehavioral sequelae of lithium exposure during lactation exist. The AAP discourages the use of lithium during lactation and suggests breastfeeding should be undertaken with caution due to lithium infant toxicity (Newport et al. 2001). Two issues regarding breast-feeding during lithium treatment include concern about rapid dehydration in neonates (Newport et al. 2001) and diminished renal clearance, both of which can elevate lithium levels (Schou et al. 1973).

Schou and Amdisen (1973) reported eight cases of children breastfed by women receiving lithium treatment. The milk/plasma ratio varied from 0.24 to 0.67 , i.e., similar to that reported by Sykes and coworkers (1976). Concentrations in the mother's serum were 1.5-5.6 times those in the child's serum. No firm conclusions were drawn regarding the safety of continuing to breastfeed during lithium therapy. On the one hand it was noted that exposure to low levels in breast milk would be unlikely to do any harm, yet any unnecessary exposure to drugs is undesirable. In later statements Schou thought it advisable that women should bottle-feed not breastfeed their children.

Sodium Valproate: Lactation appears to be safe in mothers maintained on SV. The American Academy of Neurology advocates breast-feeding while on SV (Holmes et al. 2001). Serum concentrations in infants vary from $4 \%-40 \%$ of maternal levels. No adverse effects have been reported in infants whose mothers were solely on SV during lactation (Von Unruh et al. 1984; Newport et al. 2001).

CBZ : The American Academy of Neurology advocates breast-feeding while on CBZ (Newport et al. 2001). The AAP committee on medications lists both SV and CBZ as compatible with breast-feeding. The serum concentrations of CBZ in breast-feeding infants ranged from $6 \%-65 \%$ of maternal levels (Chaudron 2000).
LTG \& TPM: Findings concerning serum concentrations of LTG in nursing infants are inconclusive. LTG is metabolized exclusively by glucuronidation, and this process is undeveloped in the fetus and neonate. Thus LTG is not recommended for use during lactation (Ohman et al. 2000) as is topiramate.

\section{BZDs}

Oxazepam has a 0.1-0.3 milk-to-plasma ratio, while fetuses whose mothers were taking lorazepam were exposed to $2.2 \%$ of the maternal doses. Neonates metabolize medications more slowly; potentially resulting in toxic serum levels. Thus, long-term use of BZDs by a breast-feeding mother could potentially lead to a buildup of the drug in the infant. If an infant experiences sedation or other signs of BZD toxicity, breast-feeding should be discontinued (Newport et al. 2001).

The use of long-acting benzodiazepines, such as diazepam and clobazam, is contraindicated in breastfeeding mothers and all other BZDs are to be used with caution. If a benzodiazepine is needed during breastfeeding, then a short-acting one, such as midazolam, oxazepam, pinazepam, or lormetazepam, should be used. However Zaleplon, Zolpidem and Zopiclone can be safely used (Fortinguerra et al. 2009).

\section{CONCLUSION}

It is known, that with most antidepressants, infant drug exposure is generally higher through placental passage than through breast milk (Eberhard-Gran et al. 2006). Thus, if a woman has taken a medication during pregnancy, it makes sense to continue with that medication during breastfeeding to minimize the number of medications to which the infant is exposed. General clinical recommendations for mothers include taking the antidepressant immediately after breastfeeding and prior to the infant's sleep time to minimize exposure to peak drug concentrations (Burt et al. 2001). 
The process of breastfeeding itself can influence how much drug enters the infant's system. Suckling, time on each breast, amount consumed per feed, feeding intervals and the interval between drug consumption and feeding all need to be considered (Welch and Findlay, 1981). Drug excretion of less than $10 \%$ is generally considered compatible with breastfeeding as it is unlikely to lead to dose related adverse events in the infant (Bennett and Jensen 1996). Finally, since breast feeding is an important factor in child development, especially for developing countries like India, clinicians should be mindful of its benefit and not just the risk of the medications.

\section{REFERENCES}

Aichhorn W, Whitworth AB, Weiss U, Stuppaeck C. Mirtazapine and breast-feeding. Am J Psychiatry. 2004 Dec;161(12):2325.

Barnas C, Bergant A, Hummer M, Saria A, Fleischhacker WW. Clozapine concentrations in maternal and fetal plasma, amniotic fluid, and breast milk. Am J Psychiatry. 1994 Jun;151(6):945.

Buist A, Norman TR, Dennerstein L. Breastfeeding and the use of psychotropic medication: a review. J Affect Disord. 1990 Jul;19(3):197-206.

Burt VK, Suri R, Altshuler L, Stowe Z, Hendrick VC, Muntean E. The use of psychotropic medications during breast-feeding. Am J Psychiatry. 2001 Jul;158(7):1001-9.

Chaudron LH. When and how to use mood stabilizers during breastfeeding. Prim Care Update Ob Gyns. 2000 May 1;7(3):113-117.

Croke S, Buist A, Hackett LP, Ilett KF, Norman TR, Burrows GD. Olanzapine excretion in human breast milk: estimation of infant exposure. Int J Neuropsychopharmacol. 2002 Sep;5(3):243-7.

Davis MF, Miller HS, Nolan PE Jr. Bupropion levels in breast milk for 4 mother-infant pairs: more answers to lingering questions. J Clin Psychiatry. 2009 Feb;70(2):297-8.

Dellisch H. Children of schizophrenic mothers. Acta Paedopsychiatr. 1989;52(4):266-70.

Eberhard-Gran M, Eskild A, Opjordsmoen S. Use of psychotropic medications in treating mood disorders during lactation : practical recommendations. CNS Drugs. 2006;20(3):187-98.

Epperson CN, Czarkowski KA, Ward-O'Brien D, Weiss E, Gueorguieva R, Jatlow P, Anderson GM. Maternal sertraline treatment and serotonin transport in breast-feeding motherinfant pairs. Am J Psychiatry. 2001 Oct;158(10):1631-7.

Epperson CN, Jatlow PI, Czarkowski K, Anderson GM. Maternal fluoxetine treatment in the postpartum period: effects on platelet serotonin and plasma drug levels in breastfeeding mother-infant pairs. Pediatrics. 2003 Nov;112(5):e425.

Field T. Breastfeeding and antidepressants. Infant Behav Dev. 2008 Sep;31(3):481-7.
Fortinguerra F, Clavenna A, Bonati M. Psychotropic drug use during breastfeeding: a review of the evidence. Pediatrics. 2009 Oct;124(4):e547-56.

Gentile S. Infant safety with antipsychotic therapy in breastfeeding: a systematic review. J Clin Psychiatry. 2008 Apr;69(4):666-73.

Gentile S. Prophylactic treatment of bipolar disorder in pregnancy and breastfeeding: focus on emerging mood stabilizers. Bipolar Disord. 2006 Jun;8(3):207-20.

Holmes LB1, Harvey EA, Coull BA, Huntington KB, Khoshbin S, Hayes AM, Ryan LM. The teratogenicity of anticonvulsant drugs. N Engl J Med. 2001 Apr 12;344(15):1132-8.

Ilett KF, Hackett LP, Dusci LJ, Roberts MJ, Kristensen JH, Paech M, Groves A, Yapp P. Distribution and excretion of venlafaxine and $\mathrm{O}$-desmethylvenlafaxine in human milk. $\mathrm{Br}$ J Clin Pharmacol. 1998 May;45(5):459-62.

Ilett KF, Hackett LP, Kristensen JH, Vaddadi KS, Gardiner SJ, Begg EJ. Transfer of risperidone and 9-hydroxyrisperidone into human milk. Ann Pharmacother. 2004 Feb;38(2):273-6.

Kasper S, Hale A, Azorin JM, Möller HJ. Benefit-risk evaluation of olanzapine, risperidone and sertindole in the treatment of schizophrenia. Eur Arch Psychiatry Clin Neurosci. 1999;249 Suppl 2:II1-II14.

Kirchheiner J, Berghöfer A, Bolk-Weischedel D. Healthy outcome under olanzapine treatment in a pregnant woman. Pharmacopsychiatry. 2000 Mar;33(2):78-80.

Klinger G, Stahl B, Fusar-Poli P, Merlob P. Antipsychotic drugs and breastfeeding. Pediatr Endocrinol Rev. 2013 MarApr;10(3):308-17.

Kris EB, Carmichael DM. Chlorpromazine maintenance therapy during pregnancy and confinement. Psychiatr Q. 1957;31(4):690-5.

Matheson I, Pande H, Alertsen AR. Respiratory depression caused by N-desmethyldoxepin in breast milk. Lancet. 1985 Nov 16;2(8464):1124.

Matheson I, Skjaeraasen J. Milk concentrations of flupenthixol, nortriptyline and zuclopenthixol and between-breast differences in two patients. Eur J Clin Pharmacol. 1988;35(2):217-20.

Mendhekar DN, Sunder KR, Andrade C. Aripiprazole use in a pregnant schizoaffective woman. Bipolar Disord. 2006 Jun;8(3):299-300.

Mendhekar DN. Possible delayed speech acquisition with clozapine therapy during pregnancy and lactation. J Neuropsychiatry Clin Neurosci. 2007 Spring;19(2):196-7.

Merlob P, Stahl B, Sulkes J. Paroxetine during breast-feeding: infant weight gain and maternal adherence to counsel. Eur J Pediatr. 2004 Mar;163(3):135-9.

Misri S, Corral M, Wardrop AA, Kendrick K. Quetiapine augmentation in lactation: a series of case reports. J Clin Psychopharmacol. 2006 Oct;26(5):508-11.

Misri S, Kim J, Riggs KW, Kostaras X. Paroxetine levels in postpartum depressed women, breast milk, and infant serum. J Clin Psychiatry. 2000 Nov;61(11):828-32. 


\section{Psychotropic drugs during lactation}

Newport DJ, Wilcox MM, Stowe ZN. Antidepressants during pregnancy and lactation: defining exposure and treatment issues. Semin Perinatol. 2001 Jun;25(3):177-90.

Nishizawa O, Sakumoto K, Hiramatsu K, Kondo T. Effectiveness of comprehensive supports for schizophrenic women during pregnancy and puerperium: preliminary study. Psychiatry Clin Neurosci. 2007 Dec;61(6):665-71.

Ohman I1, Vitols S, Tomson T. Lamotrigine in pregnancy: pharmacokinetics during delivery, in the neonate, and during lactation. Epilepsia. 2000 Jun;41(6):709-13.

Ohman R, Hägg S, Carleborg L, Spigset O. Excretion of paroxetine into breast milk. J Clin Psychiatry. 1999 Aug;60(8):519-23.

Pinkofsky HB, Fitz-Gerald MJ, Reeves RR. Psychotropic treatment during pregnancy. Am J Psychiatry. 1997 May;154(5):718-9.

Rampono J, Kristensen JH, Ilett KF, Hackett LP, Kohan R. Quetiapine and breast feeding. Ann Pharmacother. 2007 Apr;41(4):711-4.

Schlotterbeck P, Saur R, Hiemke C, Gründer G, Vehren T, Kircher $\mathrm{T}$, Leube D. Low concentration of ziprasidone in human milk: a case report. Int J Neuropsychopharmacol. 2009 Apr;12(3):437-8.

Schou M, Amdisen A, Steenstrup OR. Lithium and pregnancy. II. Hazards to women given lithium during pregnancy and delivery. Br Med J. 1973 Apr 21;2(5859):137-8.

Schou M, Amdisen A. Lithium and pregnancy. 3. Lithium ingestion by children breast-fed by women on lithium treatment. Br Med J. 1973 Apr 21;2(5859):138.

Schubert EW, McNeil TF. Prospective study of adult mental disturbance in offspring of women with psychosis. Arch Gen Psychiatry. 2003 May;60(5):473-80.
Schubert EW, McNeil TF. Prospective study of neurological abnormalities in offspring of women with psychosis: birth to adulthood. Am J Psychiatry. 2004 Jun;161(6):1030-7.

Stowe ZN, Hostetter AL, Owens MJ, Ritchie JC, Sternberg K, Cohen LS, Nemeroff CB. The pharmacokinetics of sertraline excretion into human breast milk: determinants of infant serum concentrations. J Clin Psychiatry. 2003 Jan;64(1):7380.

Stowe ZN1, Cohen LS, Hostetter A, Ritchie JC, Owens MJ, Nemeroff CB. Paroxetine in human breast milk and nursing infants. Am J Psychiatry. 2000 Feb;157(2):185-9.

Sykes PA, Quarrie J, Alexander FW. Lithium carbonate and breast-feeding. Br Med J. 1976 Nov 27;2(6047):1299.

von Unruh GE, Froescher W, Hoffmann F, Niesen M. Valproic acid in breast milk: how much is really there? Ther Drug Monit. 1984;6(3):272-6.

Weissman AM1, Levy BT, Hartz AJ, Bentler S, Donohue M, Ellingrod VL, Wisner KL. Pooled analysis of antidepressant levels in lactating mothers, breast milk, and nursing infants. Am J Psychiatry. 2004 Jun;161(6):1066-78.

Welch RM, Findlay JW. Excretion of drugs in human breast milk. Drug Metab Rev. 1981;12(2):261-77.

Wiles DH, Orr MW, Kolakowska T. Chlorpromazine levels in plasma and milk of nursing mothers. Br J Clin Pharmacol. 1978 Mar;5(3):272-3.

Yoshida K, Smith B, Craggs M, Kumar R. Neuroleptic drugs in breast-milk: a study of pharmacokinetics and of possible adverse effects in breast-fed infants. Psychol Med. 1998 Jan;28(1):81-91. 